\title{
Spermicidal and anti-Trichomonas vaginalis activity of Brazilian Sapindus saponaria
}

\author{
Edilson Damke ${ }^{1}$, Joyce K Tsuzuki ${ }^{2}$, Francieli Chassot ${ }^{1}$, Diógenes AG Cortez ${ }^{2}$, Izabel CP Ferreira ${ }^{2}$, \\ Cristiane SS Mesquita ${ }^{3}$, Vânia RS da-Silva', Terezinha IE Svidzinski ${ }^{3}$ and Márcia EL Consolaro ${ }^{\text {** }}$
}

\begin{abstract}
Background: Sapindus saponaria is used traditionally for curing ulcers, external wounds and inflammations. The spermicidal and anti-Trichomonas activity of S. saponaria and its effect on Lactobacillus acidophilus were evaluated.

Methods: Water-ethanol (WE) and butanolic (BE) extracts, as well as a purified sample of saponins (SP) from S. saponaria were tested for spermicidal and anti-Trichomonas activity and for their effect on L. acidophilus.

Results: WE, BE and SP immobilized spermatozoa at a minimum effective concentration (MEC) of 2.5 (gram \%) for extracts and 1.25 (gram \%) for SP. The effective concentrations that caused 50\% immobilization of spermatozoa $\left(\mathrm{EC}_{50}\right.$ ) were 0.5 (gram \%) for WE and SP, and 0.1 (gram \%) for BE. The compounds were effective against Trichomonas vaginalis (Minimum Inhibitory Concentration $=0.156 \mathrm{mg} / \mathrm{mL}$ for WE and BE, and $0.078 \mathrm{mg} / \mathrm{mL}$ for SP against a clinical strain (CS); and 0.312, 0.156 and $0.078 \mathrm{mg} / \mathrm{mL}$ for WE, BE and SP, respectively, against an ATCC strain). In all concentrations tested, the growth of L. acidophilus was not reduced.
\end{abstract}

Conclusion: The in vitro study proved the spermicidal and anti-Trichomonas activity of S. saponaria. Complementary in vivo studies should be made for establish the use as a vaginal spermicide, particularly in Brazil and Latin America.

Keywords: Sapindus saponaria, Saponins, Spermicidal, Anti-Trichomonas vaginalis activity, Contraceptive

\section{Background}

The sexually transmitted diseases (STDs) are among the most common public-health problems in Brazil and worldwide, and are currently considered the main factor facilitating sexual transmission of HIV/AIDS [1-3]. Most family planning methods, such as oral and injectable hormonal contraceptives, implants, intrauterine devices (IUDs) and sterilization, for example, are effective against unwanted pregnancy, but do not protect against STDs. Safe, effective, acceptable, and self-administered topical preparations with both microbicidal and spermicidal activity are likely to have a major positive impact on reproductive health, especially in areas with a high prevalence of STDs, including HIV infection [4].

To our knowledge, no studies have evaluated the spermicidal activity, against STDs or the effect on the vaginal microbiota for the wingleaf soapberry Sapindus saponaria.

\footnotetext{
* Correspondence: melconsolaro@gmail.com

1 Department of Clinical Analysis and Biomedicine, Division of Clinical

Cytology, State University of Maringá, Maringá, Paraná 4860, Brazil

Full list of author information is available at the end of the article
}

This is a native plant of Brazil, and belongs to the same family as the Indian soapberry Sapindus mukorossi, a native Indian plant for which the saponin fraction isolated from the fruit pericarp has shown very promising spermicidal activity [5,6]. The fruit of Sapindus saponaria L. (Sapindaceae), a medium-sized tropical tree, is used by population as soap for washing clothes, and for curing ulcers, external wounds and inflammations [7]. Scientific works has shown antimicrobial activity [8-10], but has been little studied. In a recent study, members of our research group isolated and identified the principal constituents of the $\mathrm{n}-\mathrm{BuOH}$ saponins, saponins ( $\mathrm{S} 1$ and S2), and also an acyclic oligoglycoside. The same group also demonstrated excellent inhibitory action in vitro and in vivo of the water-ethanol (WE) and butanolic (BE) extracts against the yeasts Candida albicans and non-C. albicans isolated from patients with vulvovaginal candidiasis (VVC). The extracts showed no toxicity to HeLa cervical cells $[11,12]$, signaling the possibility of using this plant as an antifungal agent in this pathology.

\section{() Biomed Central}

(c) 2013 Damke et al.; licensee BioMed Central Ltd. This is an Open Access article distributed under the terms of the Creative Commons Attribution License (http://creativecommons.org/licenses/by/2.0), which permits unrestricted use, distribution, and reproduction in any medium, provided the original work is properly cited. 
A nonionic detergent, nonoxynol-9 (N-9) is widely used as a spermicidal compound. It dissolves the lipid components in the cell membrane of spermatozoa and causes their death or inactivation. N-9 also disrupts the membrane of bacteria, viruses and epithelial cells. Its in vitro activity against HIV and other STDs, reported in the past [13], has not been confirmed in more recent clinical trials. These new findings eliminated the possibility of a role for N-9 in HIV prevention. In addition, a number of studies have indicated that N-9 and other nonionic detergents are potent in vitro inhibitors of Lactobacillus species native to the vagina [14-16]. Consequently, repeated use of N-9 containing spermicides is likely to increase the susceptibility of the vagina to STDs including AIDS. In contrast, some studies indicate that saponins of Sapindus mukorossi are far less toxic to Lactobacillus species compared to N-9 [17]; show potent microbicidal activity against Trichomonas vaginalis [18], Neisseria gonorrhoeae, Escherichia coli, and HIV-1; and prevent the transmission of the herpes simplex virus and Chlamydia trachomatis [19].

The present study evaluated the spermicidal and antiTrichomonas activity of WE and BE extracts, as well as the purified sample of saponins (SP) of Sapindus saponaria and their effects on Lactobacillus acidophilus, a common member of the vaginal microbiota.

\section{Methods}

\section{Plant and extracts/saponins obtainment}

Dry pericarps of the fruits of $S$. saponaria were collected on the campus of the State University of Maringá, Paraná, Brazil (UEM). The plant was identified by staff members of the UEM Department of Botany, and an exsiccate was deposited in the Herbarium of this institution (HUM 11710).

To obtain the WE extract, dried pericarps of the fruits (450.0 g) of $S$. saponaria were ground and extracted with $\mathrm{EtOH}: \mathrm{H}_{2} \mathrm{O}(9: 1)$ at room temperature, by dynamic maceration with constant mechanical stirring. Extraction was carried out in an amber flask, maintained at ambient temperature, for six consecutive days, $6 \mathrm{~h}$ per day. The extract was concentrated under low pressure in a rotary evaporator, at a temperature of $40^{\circ} \mathrm{C}$. After elimination of the solvent, the extract was frozen in liquid nitrogen and lyophilized in a Martin Christ Alpha 1-2 freeze dryer. The lyophilized extract was stored in a closed amber plastic flask and kept frozen. The WE of the pericarp (50.15 g) was chromatographed in a column $(\mathrm{ji}=4.0 \mathrm{~cm}$ ) of silica gel 60 (Merck, Darmstadt, Germany), and eluted with solvents of increasing polarity including hexane, dichloromethane, ethyl acetate, and methanol (Merck, Darmstadt, Germany). The solvents were evaporated at a temperature of $40^{\circ} \mathrm{C}$, frozen in liquid nitrogen, and lyophilized in a Martin Christ Alpha 1-2 freeze dryer. The lyophilized dichloromethane, hexane, ethyl acetate, and methanol fractions were stored in closed containers and kept frozen.
To obtain the BE extract, the methanol fraction was suspended in $\mathrm{H}_{2} \mathrm{O}$ and extracted with n-butanol, which after evaporation gave a solid residue (28.9 g) (BE), which was also lyophilized.

To obtain the SP, two treatments were performed on the column with BE, the first on silica gel in 'flash' chromatography and the second in a silica-gel column with increasing polarity solvents, to obtain two sesquiterpene saponins and also one acyclic oligoglycoside. The structures were established by spectroscopic methods $\left({ }^{1} \mathrm{H}\right.$ and ${ }^{13} \mathrm{C}$ NMR, HSQC, HMBC, and ESI/MS) and by comparing them with literature data $[8,10]$.

\section{Spermicidal activity}

The spermicidal activity was determinate by the minimum effective concentration (MEC) of each compound that causes total immobilization of spermatozoa, indicating not viability, the effective concentration of the compounds that causes $50 \%$ immobilization of spermatozoa $\left(\mathrm{EC}_{50}\right)$, supravital staining and hypo-osmotic swelling test.

\section{Chemicals and plant components}

WE and BE extracts, and SP obtained from S. saponaria were tested. N-9 (Preserv ${ }^{\circ}(2 \%-20 \mathrm{mg} / \mathrm{g})$ - Blausiegel, positive control) was used as the spermicidal solution. The lyophilized and frozen extracts of $S$. saponaria were dissolved in sterile distilled water just before the experiments. All other chemicals and biochemicals were purchased from Sigma-Aldrich, USA.

\section{Semen samples}

Fresh human semen samples collected by masturbation were obtained from healthy male donors above 21 (mean $=35.3 \pm 2.1$ ) years old. The samples were allowed to liquefy at $37^{\circ} \mathrm{C}$ for $30 \mathrm{~min}$. The volume, $\mathrm{pH}$, viscosity and morphology of the semen were determined as per World Health Organization guidelines [20]. Semen samples with a spermatozoa count of $>60$ million per $\mathrm{mL},>65 \%$ motility, $>60 \%$ normal physiology, and a normal pH (7.48.0 ), viscosity and volume were used for tests. The analyses were made by the Carl Zeiss PrimoStar (Gottingen, Germany) optical microscope. This research was approved by the Committee for Ethics in Research Involving Humans at the State University of Maringá, Paraná, Brazil (reports No. 132.777/2012) in compliance with the Helsinki Declaration and each male donors involved had signed the consent form.

\section{MEC and $E_{50}$ determination}

The MEC of each compound that causes total immobilization of spermatozoa, indicating not viability, was determined by the Sander-Cramer assay [21]. WE, BE and SP of $S$. saponaria were tested at an initial concentration of $10 \mathrm{mg} / \mathrm{ml}$ and diluted in hemolysis tubes at the ratio of 1:2 
to $1: 32$ with sterile saline. Sterile saline solution was used for the negative control. Briefly, $0.1 \mathrm{~mL}$ of liquefied semen was added to $0.4 \mathrm{~mL}$ of spermicidal solution, N-9 or saline and vortexed for $10 \mathrm{~s}$. A wet mount was immediately prepared on a glass slide and examined under an optic microscope. The weakest dilution that completely immobilized all the spermatozoa in $20 \mathrm{~s}$ was recorded as MEC in gram $\%(w / v)$. This was confirmed in three individual semen samples and five fields of view.

The $\mathrm{EC}_{50}$ was determined in a similar manner using serial dilutions (1:5 ratio) of spermicidal solutions at MEC. The weakest dilution that inhibited spermatozoa motility to $\sim 50 \%$ of the control (sterile saline only) in gram $\%(\mathrm{w} / \mathrm{v})$ was recorded as $\mathrm{EC}_{50}$. This was confirmed in three individual samples and five fields.

\section{Supravital staining and hypo-osmotic swelling test}

For supravital staining, $10 \mu \mathrm{L}$ of $\mathrm{MEC}$ and $\mathrm{EC}_{50}$ tubes was added to new hemolysis tubes containing eosin nigrosin (1:2). The samples were mixed and a thin smear was prepared on a glass slide and heat-dried. The dead spermatozoa show positive red staining with eosin and the live spermatozoa not staining, show a white color in contrast with the nigrosin background dye. The numbers of unstained and stained spermatozoa were counted in a total of 200 sperm [20].

For the hypo-osmotic swelling test, $0.1 \mathrm{~mL}$ of semen was treated with $0.5 \mathrm{~mL}$ of sterile saline (control) or spermicidal solution (at MEC) for $1 \mathrm{~min} / 37^{\circ} \mathrm{C}$. After centrifugation at $1000 \mathrm{rpm}$ for $5 \mathrm{~min}$, the sperm pellet was treated with $0.5 \mathrm{~mL}$ of hypo-osmotic solution $(75 \mathrm{mM}$ fructose, $25 \mathrm{mM}$ sodium citrate) for $30 \mathrm{~min} / 37^{\circ} \mathrm{C}$. The number of spermatozoa exhibiting characteristic swelling or tail coiling (live) was counted for a total of 200 spermatozoa under an optical microscope.

\section{Anti-Trichomonas activity Chemicals and trophozoites}

The $T$. vaginalis cultures were a clinical strain (CS) and the ATCC strain. WE, BE and SP of S. saponaria were tested for anti-Trichomonas activity. The lyophilized and frozen extracts and SP were dissolved in sterile distilled water just before the experiments. TYM- Trypticase-Yeast extract-Maltose culture medium, supplemented by fetal calf serum, vitamin mixture, penicillin-streptomycin mixture, JC-1 (1,10,3,30-tetraethyl benzimidazole carbocyanines iodine), CCCP-1 (carbonyl cyanide m-chlorophenylhydrazone), proteinase $\mathrm{K}$ and dimethylsulfoxide (DMSO) were purchased from Sigma-Aldrich, USA.

\section{T. vaginalis culture}

The trophozoites were grown for $48 \mathrm{~h}$ in standard TYM medium (pH6.8) supplemented with 10\% FCS, vitamin mixture and $100 \mathrm{U} / \mathrm{mL}$ penicillin/streptomycin mixture at $37^{\circ} \mathrm{C}$ in $15 \mathrm{~mL}$ screw-stoppered glass tubes [18]. Then, a suspension was prepared containing $1.0 \times 10^{5}$ to $5.0 \times 10^{5}$ trophozoites $/ \mathrm{mL}$, in sterile distilled water, determined in a Neubauer chamber.

\section{Susceptibility assay}

Susceptibility of T. vaginalis was tested as described [22]. Minimum inhibitory concentration of the extracts or SP at which all cells were found dead was considered as its MIC [18]. To evaluate the anti-Trichomonas activity and determine the MIC, the WE, BE and SP of S. saponaria were used in an initial concentration of $10 \mathrm{mg} / \mathrm{mL}$ and diluted in hemolysis tubes at the rate of $1: 2$ to $1: 32$ with sterile saline. Briefly, $1.5 \mathrm{~mL}$ of the suspension with trophozoites (CS and ATCC strains) was incubated in the presence of serially diluted WE, BE and SP $(1.5 \mathrm{~mL})$ in TYM culture medium $(1.5 \mathrm{~mL})$ at $35^{\circ} \mathrm{C} / 24 \mathrm{~h}$. A tube without added trophozoites was used as negative control, and a tube without added extracts or SP was used as positive control. Cells were checked for viability under the optical microscope.

\section{The effect on Lactobacillus acidophilus Chemicals and microorganisms}

Rogosa SL agar (Sigma-Aldrich, USA) and L. acidophilus (kindly supplied by the Oswaldo Cruz Institute Foundation, Rio de Janeiro, Brazil) were used. WE, BE and SP of $S$. saponaria were evaluated for their effect on L. acidophilus. The lyophilized and frozen extracts and SP were dissolved in sterile distilled water just before the experiments.

\section{Lactobacillus culture}

Rogosa SL agar (7.5\%; containing $0.132 \%$ acetic acid) plates were prepared with (experimental) or without (negative control) the addition of spermicidal agents. Plates containing $10.0,5.0,2.5,1.25,0.625,0.310$ or $0.165 \mathrm{mg}$ of WE, $\mathrm{BE}$ or SP were inoculated with L. acidophilus (1 to $5 \times 10^{8}$ CFU (colony-forming units) $/ \mathrm{mL}$ ) and incubated at $37^{\circ} \mathrm{C}$ in $5 \% \mathrm{CO}_{2}$ and $95 \%$ air for $72 \mathrm{~h}$. Control plates were inoculated simultaneously and incubated similarly. Number and size of colonies were recorded at the end of the experiment.

\section{Statistical analysis}

All experiments were performed three times. The data are expressed as mean \pm SEM and analyzed by one-way analysis of variance. $\mathrm{p}<0.05$ was considered as the criterion for statistical significance.

\section{Results}

\section{Plants and components}

The presence of two acetylated triterpene saponins was confirmed: saponin S1, hederagenin-3-O- (3,4-di-Oacetylb-D-xylopyranosyl)- ( $\left.{ }^{\oplus} 3\right)$-a-L-ramnopyranosyl- $\left(1^{\oplus} 2\right)$-a-L- 
arabinopyranoside; and saponin S2, hederagenin-3-O-(4-Oacetyl-b-D-xylopyranosyl)-(1 $\left.{ }^{\circ} 3\right)$-a-Lramnopyranosyl-( $\left.1^{\circ} 2\right)$-aL-rabinopyranoside; and also an acyclic oligoglycoside-1 (OGSA-1) in WE and BE, and S1 and S2; in SP, saponin S1 (A) and saponin S2 (B) as previously described [11] (Figure 1).

\section{Spermicidal activity}

The results indicated that the concentrations of $2.5 \mathrm{mg} / \mathrm{mL}$ of WE and BE, and $1.25 \mathrm{mg} / \mathrm{mL}$ of SP were effective in producing total immobilization, indicating not viability of $100 \%$ of spermatozoa (Figure 2). Therefore, the MEC for the extracts was 2.5 (gram \%) and for the SP was 1.25 (gram \%). There was not viability for N-9, and for the negative control, the viability was $65 \%$. At MEC for WE, BE and SP, $100 \%$ of spermatozoa showed positive red staining

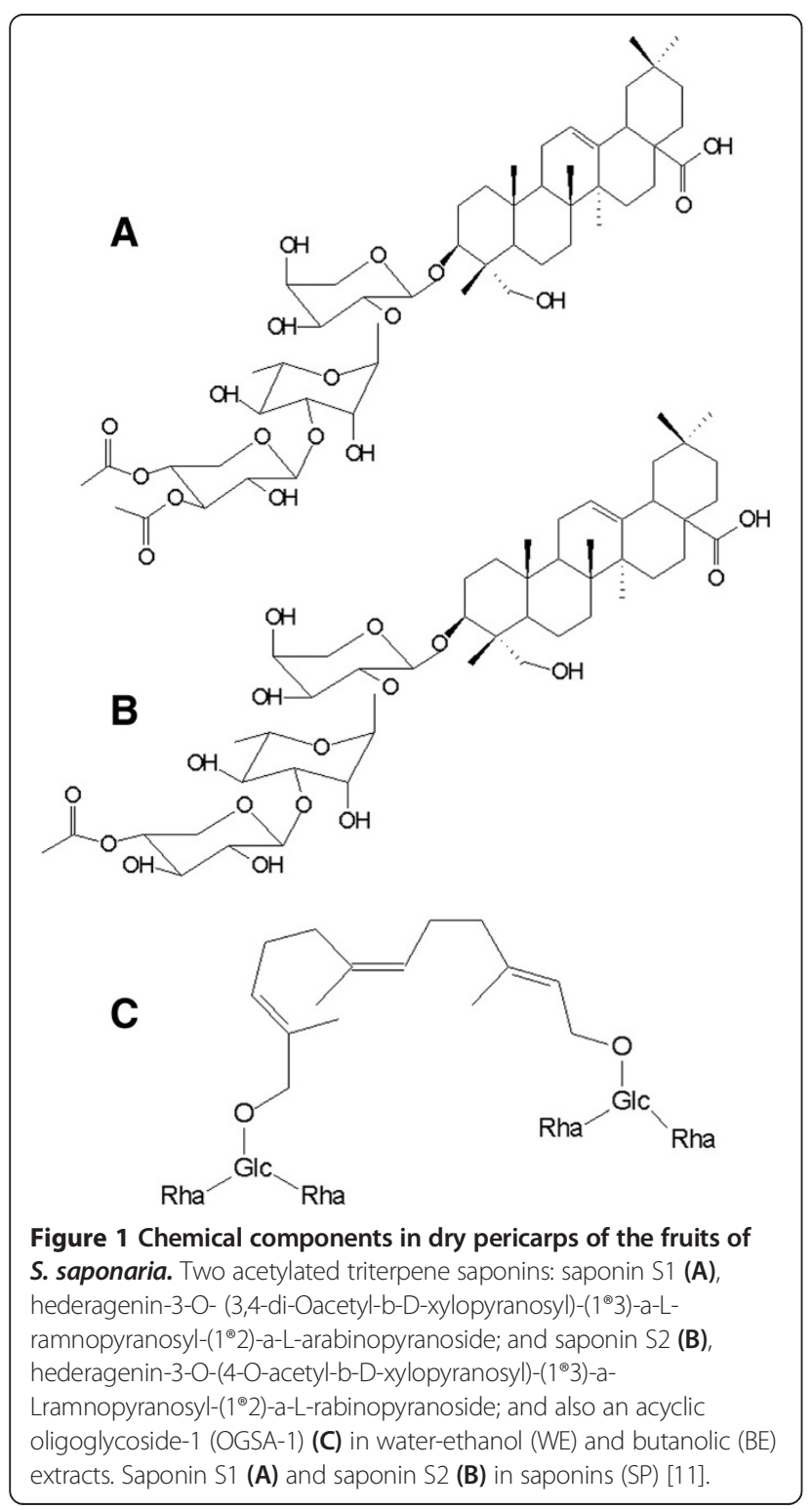

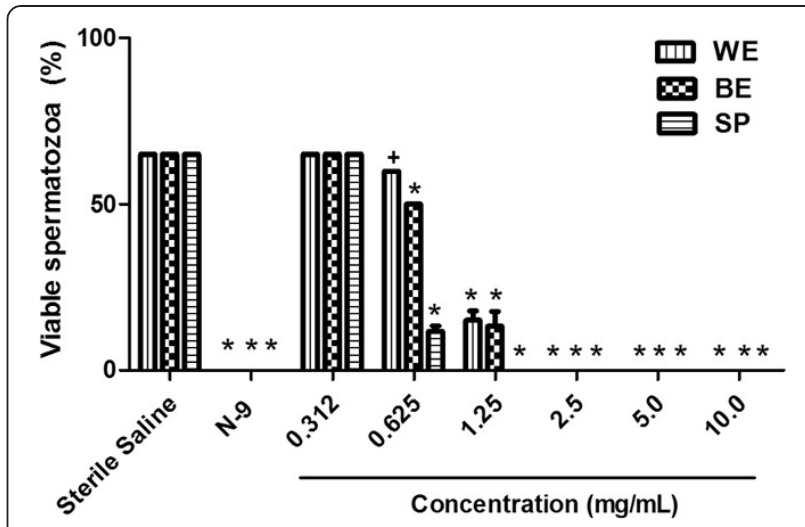

Figure 2 Effects of water-ethanol (WE) and butanolic (BE) extracts, and individual saponins (SP) of Sapindus saponaria on sperm motility in human semen. Mean \pm SEM of percentage of viable spermatozoa (mobile) in different concentrations of WE, BE and SP, in three independent experiments. Nonoxynol-9 (N-9; 2\%- 20 mg/g) was used as positive control or spermicidal solution. $+p<0.05,{ }^{*} p<0.001$.

with eosin, indicating death (Figure 3B), and nearly 100\% spermatozoa showed negative hypo-osmotic swelling after treatment with both extracts and SP, indicating complete membrane damage.

The concentrations needed to produce immobility of $50 \%$ of spermatozoa at MEC were $0.5 \mathrm{mg} / \mathrm{mL}$ for WE (Figure $4 \mathrm{~A}$ ) and SP (Figure $4 \mathrm{C}$ ), and $0.1 \mathrm{mg} / \mathrm{mL}$ for $\mathrm{BE}$ (Figure 4B). Therefore, the $\mathrm{EC}_{50}$ was 0.5 (gram \%) for WE and SP and 0.1 (gram \%) for BE. Supravital staining confirmed that $50 \%$ of spermatozoa were dead with $\mathrm{EC}_{50}$ values.

\section{Anti-Trichomonas activity}

The results showed that both Trichomonas strains (CS and ATCC) were inhibited by the WE, BE and SP. The minimum concentrations with no live trophozoites (MIC) for the CS strain were $0.156 \mathrm{mg} / \mathrm{mL}$ for WE and BE, and $0.078 \mathrm{mg} / \mathrm{mL}$ for SP. The MICs for the ATCC strain were $0.312 \mathrm{mg} / \mathrm{mL}$ for WE, $0.156 \mathrm{mg} / \mathrm{mL}$ for BE and $0.078 \mathrm{mg} /$ $\mathrm{mL}$ for SP (Table 1).

\section{The effect on L. acidophilus}

The growth of $L$. acidophilus was not affected by the two extracts and SP of S. saponaria compared with the control (Figure 5).

\section{Discussion}

Considering the need to find spermicidal agents that are more effective in protecting against pregnancy as well as STDs, and are also less toxic, in this study we evaluated the spermicidal and anti-Trichomonas activity of WE and BE extracts, as well as the SP of Sapindus saponaria and its effect on Lactobacillus acidophilus, a common member of the vaginal microbiota. 


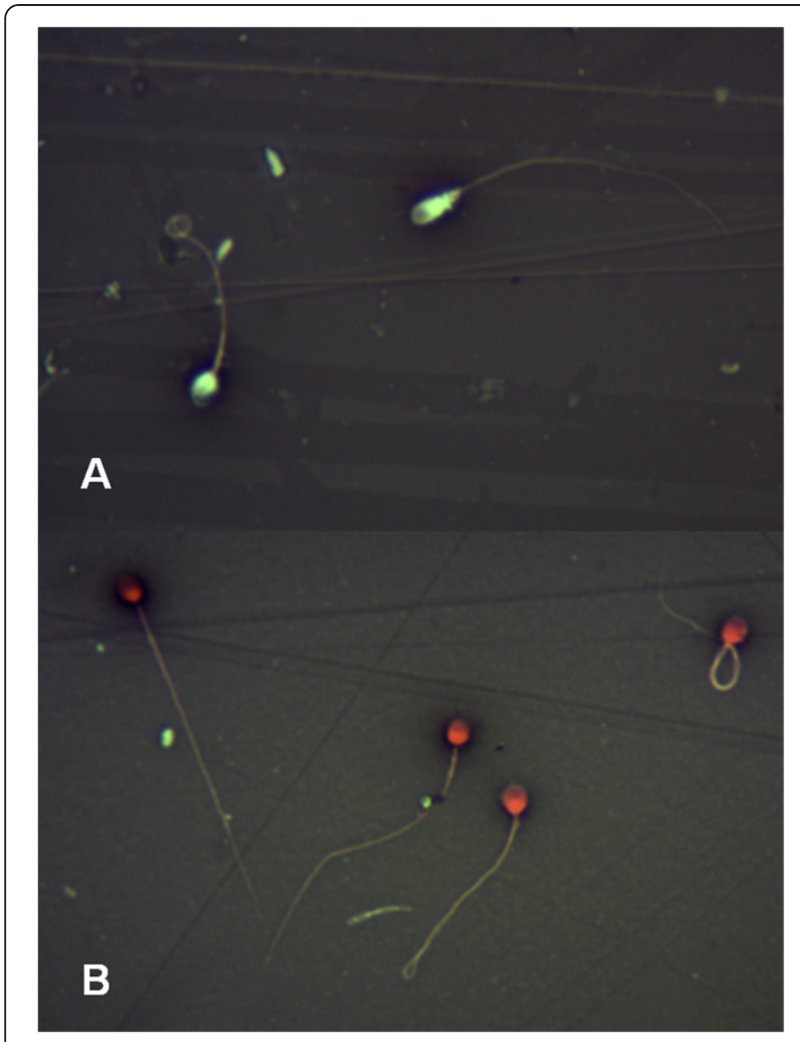

Figure 3 Sperm imagens of supravital staining containing eosin - nigrosin (1:2). In the absence of water-ethanol (WE) and butanolic (BE) extracts, and saponins (SP) of Sapindus saponaria, the spermatozoa showed negative red staining, indicating live (A). At MEC for WE, BE and SP, 100\% of spermatozoa showed positive red staining with eosin, indicating death (B). [magnification, x1000].

S. saponaria is popularly known as "sabão-de-macaco", "saboeiro", "saboneteiro", "fruta de sabão" and "sabãode-soldado" [23] and is found in South and Central America, from forests to "cerrado", a vast tropical savanna ecoregion. In Brazil, it is found from Para State to Rio Grande do Sul State [7,23]. This plant has shown antimicrobial $[8,9]$ and antifungal activities, and no toxicity to HeLa cervical cells [11,12].

In the present experiments, WE, BE and SP of $S$. saponaria were effective for total sperm immobilization (not viability) at MEC of 2.5 (gram \%) for extracts and 1.25 (gram \%) for SP. At MEC, $100 \%$ of spermatozoa showed positive red staining with eosin and negative hypo-osmotic swelling after treatment, indicating complete membrane damage and death. This result is similar to S. mukorossi, which is the best-known species of the genus Sapindus and is traditionally used in eastern medicine as a spermicide [24]. S. mukorossi shows spermicidal activity [6], which is attributed to the presence of saponins $[5,25,26]$. Similarly, saponins of other plants have been used in contraceptive formulations, either as foaming agents or as spermicidal substances $[27,28]$.

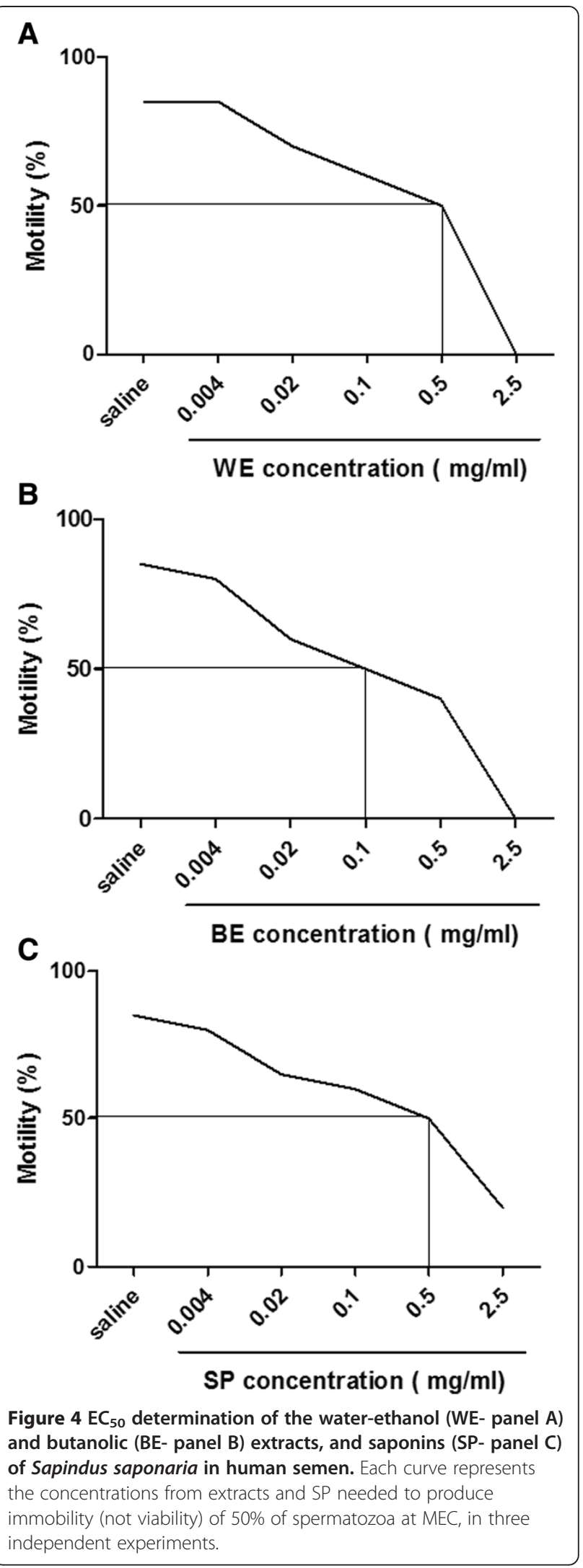


Table 1 Susceptibility of Trichomonas vaginalis to water-ethanol (WE) and butanolic (BE) extracts, and saponins (SP) of Sapindus saponaria

\begin{tabular}{|c|c|c|c|c|c|c|}
\hline \multirow{3}{*}{$\begin{array}{l}\text { Concentration } \\
(\mathrm{mg} / \mathrm{mL})\end{array}$} & \multicolumn{3}{|c|}{ Viable trophozoites $/ \mathrm{mL}$} & \multicolumn{3}{|c|}{ Viable trophozoites $/ \mathrm{mL}$} \\
\hline & \multicolumn{3}{|c|}{ CS strain } & \multicolumn{3}{|c|}{ ATCC strain } \\
\hline & WE & $\mathrm{BE}$ & SP & WE & $\mathrm{BE}$ & SP \\
\hline 0.156 & - & - & - & $7.5 \times 10^{3}$ & - & - \\
\hline 0.078 & $2.5 \times 10^{3}$ & $1.0 \times 10^{4}$ & - & $1.5 \times 10^{4}$ & $1.0 \times 10^{4}$ & - \\
\hline 0.039 & $2.5 \times 10^{3}$ & $2.5 \times 10^{4}$ & $1.5 \times 10^{4}$ & $1.25 \times 10^{4}$ & $1.75 \times 10^{4}$ & $1.25 \times 10^{4}$ \\
\hline 0.019 & $2.5 \times 10^{3}$ & $5.0 \times 10^{3}$ & $1.0 \times 10^{4}$ & $6.25 \times 10^{4}$ & $2.5 \times 10^{4}$ & $1.0 \times 10^{4}$ \\
\hline C+ & $1.5 \times 10^{4}$ & $1.25 \times 10^{4}$ & $1.5 \times 10^{4}$ & $5.25 \times 10^{4}$ & $7.5 \times 10^{3}$ & $5.5 \times 10^{4}$ \\
\hline $\mathrm{C}-$ & - & - & - & - & - & - \\
\hline
\end{tabular}

Not found viable trophozoites in concentrations at 0.312 to $10.0(\mathrm{mg} / \mathrm{mL})$ for extracts or SP.

- not found viable trophozoites.

$\mathrm{C}+$ positive control - tube without addition of extracts or SP.

C- negative control - tube without addition of trophozoites.

The spermicidal local contraceptives incorporating microbicidal activity can play a significant role in controlling STDs [6]. T. vaginalis causes trichomoniasis, which is the most prevalent non-viral human urogenital pathogen [29]. In this study, the compounds inhibited two different strains of Trichomonas vaginalis. They were effective against the CS strain (MIC $=0.156 \mathrm{mg} /$ $\mathrm{mL}$ for $\mathrm{WE}$ and $\mathrm{BE}$, and $0.078 \mathrm{mg} / \mathrm{mL}$ for $\mathrm{SP}$ ) and against the ATCC strain (MIC $=0.312,0.156$ and 0.078 $\mathrm{mg} / \mathrm{mL}$ for WE, BE and SP, respectively), and the active anti-Trichomonas concentrations were lower than its effective spermicidal concentration. This accord with observations on saponins from S. mukorossi, which exhibit

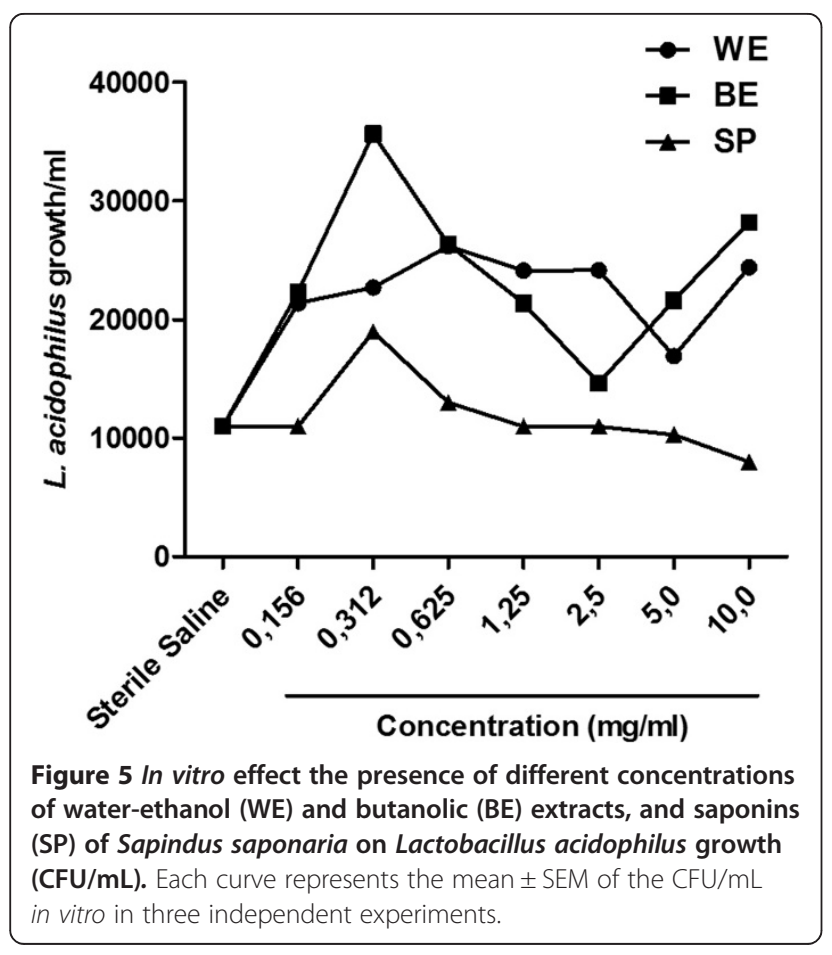

anti-Trichomonas activity at a 10 -fold lower concentration than the effective spermicide against human spermatozoa [18]. T. vaginalis is inhibited by saponins obtained from other plants [30,31], showing that the anti-Trichomonas effect could also be related to the presence of saponins.

L. acidophilus is a important organism in the vaginal microbiota, and is responsible for maintaining acidic $\mathrm{pH}$, preventing the growth of potential pathogens $[32,33]$. The ideal spermicidal agent should preserve the healthier vaginal microflora through retention of Lactobacillus. In vitro studies have shown that $\mathrm{N}-9$ is detrimental to Lactobacillus species [14-16], showing that its use could contribute for increase the incidence of STDs [34-36]. The present study showed that the WE, BE or SP of $S$. saponaria did not alter the growth of $L$. acidophilus colonies, showing that is not toxic to the common vaginal microbiota. This accord with the observations of Ojha et al. [17] who concluded that the saponins are far less toxic compared to N-9.

We acknowledge that in vivo studies are needed to completely confirm our results. One of the great challenges of research on the physiopathogenesis of diseases is to match the experimental conditions in vitro as much as possible to those in vivo, which are often much more complex [37]. However, researchers recognize that these experiments do provide an approximation to in vivo conditions [37-39].

\section{Conclusion}

In conclusion, the present study demonstrated that $S$. saponaria or its saponins could be an alternative vaginal spermicide for use in Brazil or Latin America as a whole, either alone or incorporated in condoms or spermicidal creams. In vivo studies must be carried out to evaluate its effects and toxicity, and any antimicrobial activity against other microorganisms. 


\section{Abbreviations}

WE: Water-ethanol extract of Sapindus saponaria; BE: Butanolic extract of Sapindus saponaria; SP: Purified sample of saponins from Sapindus saponaria; MEC: Minimum effective concentration; $\mathrm{EC}_{50}$ : Effective concentration that causes $50 \%$ immobilization of spermatozoa; MIC: Minimal inhibitory concentration; CS: Clinical strain; STDs: Sexually transmitted diseases; IUDs: Intrauterine devices; WC: Vulvovaginal candidiasis; N-9: Nonoxynol-9; UEM: State University of Maringá, Paraná, Brazil; CFU/mL: Colony-forming units per $\mathrm{mL}$.

\section{Competing interests}

The authors declare that they have no competing interests.

\section{Authors' contributions}

ED carried out the in vitro susceptibility tests and helped to draft the manuscript. JKT prepared the extracts. FC carried out the in vitro susceptibility tests.DAGC and ICPF analyzed the plant components and helped to draft the manuscript. CSSM carried out the in vitro susceptibility tests. TIES helped to conceive the study, participated in its design and coordination, and helped to draft the manuscript. VRSS carried out the in vitro susceptibility tests and helped to draft the manuscript. MELC carried out the cell toxicity analyses, participated in the study coordination, and helped to draft the manuscript. All authors read and approved the final manuscript.

\section{Acknowledgments}

\section{Financial support}

This work was supported by grants from Fundação Araucária de Apoio ao Desenvolvimento Cientifico e Tecnológico do Paraná (15025/2009 project).

\section{Author details}

${ }^{1}$ Department of Clinical Analysis and Biomedicine, Division of Clinical Cytology, State University of Maringá, Maringá, Paraná 4860, Brazil. 2Department of Pharmacy, State University of Maringá, Maringá, Paraná, Brazil. ${ }^{3}$ Department of Clinical Analysis and Biomedicine, Division of Medical Mycology, State University of Maringá, Maringá, Paraná, Brazil.

Received: 8 February 2013 Accepted: 25 July 2013

Published: 28 July 2013

\section{References}

1. Ministério da Saúde (Brasil), Secretaria de Atenção à Saúde Departamento de Atenção Básica: HIV/Aids, hepatites e outras DST. Brasília: Cadernos de Atenção Básica, n 18; 2006.

2. World Health Organization: Guidelines for the management of sexually transmitted infections. Geneva: World Health Organization; 2003.

3. World Health Organization: Sexually transmitted infections; 2011. www.who. int/mediacentre/factsheets/fs110/en/index.html. Accessed 16 Oct 2012

4. World Health Organization: HIV/AIDS makes dual protection a must. Prog Reprod Heal Res 2002, 59:1-8.

5. Garg S, Doncel G, Chabra S, Upadhyay SN, Talwar GP: Synergistic spermicidal activity of neem seed extract, reetha saponins and quinine hydrochloride. Contraception 1994, 50:185-190.

6. Gupta G: Microbicidal spermicide or spermicidal microbicide? Eur J Contracept Reprod Health Care 2005, 10(4):212-218.

7. Albiero ALM, Bacchi EM, Mourão KSM: Caracterização anatômica das folhas, frutos e sementes de Sapindus saponaria L. (Sapindaceae). Acta Scientiarum 2001, 23:549-560.

8. Ribeiro A, Zani CL, Alves TMA, Mendes NM, Hamburger M, Hostettmann K: Molluscicidal saponins from the pericarp of Sapindus saponaria. Int J Pharmacognosy 1995, 33:177-180.

9. Albiero ALM, Sertié JAA, Bacchi EM: Antiulcer activity of Sapindus saponaria L. in the rat. J Ethnopharmacol 2002, 82:41-44.

10. Murgu M, Rodrigues-Filho E: Hydroxilation of a hederagenin derived saponin by a Xylareaceous fungus found in fruits of Sapindus saponaria. J Braz Chem Soc 2006, 17:1281-1290.

11. Tzuzuki JK, Svidzinski TIE, Shinobu CS, Silva LFA, Rodrigues-Filho E, Cortez DAG, Ferreira ICP: Antifungal activity of the extracts and saponins from Sapindus saponaria L. Anais Ac Bras Ciências 2007, 79:577-583.

12. Damke E, Tsuzuki JK, Cortez DAG, Ferreira ICP, Bertoni TA, Batista MR, Donati L, Svidzinski TIE, Consolaro MEL: In vivo activity of Sapindus saponaria against azole-susceptible and -resistant human vaginal Candida species. BMC Complement Altern Med 2011, 11:35.

13. Cates WJ, Raymond EG, et al: Vaginal spermicides. In Contraceptive technology. 17th edition. Edited by Hatcher RA, Trussell J, Stewart F. New York: Ardent Media; 1998:357-369.

14. Klebanoff SJ: Effects of the spermicidal agent nonoxynol-9 on vaginal microflora. J Infect Dis 1992, 165:19-25.

15. McGroarty JA, Tomecjek L, Pond DG, Reid G, Bruce AW: Hydrogen peroxide production by Lactobacillus species: correlation with susceptibility to the spermicidal compound nonoxynol-9. J Infect Dis 1992, 165:1142-1144.

16. Reid G, McGroarty JA, Tomecjek L, Bruce AW: Identification and plasmid profiles of lactobacillus species from the vagina of 100 healthy women. FEMS Immun Med Microbiol 1996, 15:23-26.

17. Ojha P, Maikhuri JP, Gupta G: Effect of spermicides on Lactobacillus acidophilus in vitro- nonoxynol-9 vs Sapindus saponins. Contraception 2003, 68:135-138.

18. Tiwari P, Singh D, Singh MM: Anti-Trichomonas activity of Sapindus saponins, a candidate for development as microbicidal contraceptive. J Antimicrob Chemother 2008, 62:526-534.

19. Talwar GP, Raghuvanshi P, Mishra R, Banerjee U, Rattan A, Whaley KJ, Zeitlin L, Achilles SL, Barré-Sinoussi F, David A, Doncel GF: Polyherbal formulations with wide spectrum antimicrobial activity against reproductive tract infections and sexually transmitted pathogens. Am J Reprod Immunol 2000, 43:144-151.

20. World Health Organization: WHO Laboratory Manual for the Examination and Processing of Human Semen. 5th edition. Geneva: WHO Press; 2010.

21. Gupta G, Jain RK, Maikhuri JP, Shukla PK, Kumar M, Roy AK, Patra A, Singh V, Batra S: Discovery of substituted isoxazolecarbaldehydes as potent spermicides, acrosin inhibitors and mild anti-fungal agents. Hum Reprod 2005, 20(8):2301-2308.

22. Upcroft JA, Upcroft P: Drug susceptibility testing of anaerobic protozoa. Antimicrob Agents Chemother 2001, 45:1810-1814.

23. Lorenzi H: Árvores brasileiras: manual de identificação e cultivo de plantas arbóreas nativas do Brasil. São Paulo: Nova Odessa: Instituto Plantarum de Estudos de Flora; 2004

24. Pelegrini DD, Tsuzuki JK, Amado CAB, Cortez DAG, Ferreira ICP: Biological Activity and Isolated Compounds in Sapindus saponaria L. and other Plants of the Genus Sapindus. Lat Am J Pharm 2008, 27(6):922-927.

25. Maikhuri JP, Dwivedi AK, Dhar JD, Setty BS, Gupta G: Mechanism of action of some acrylophenones, quinolines and dithiocarbamate as potent, non-detergent spermicidal agents. Contraception 2003, 67:403-408

26. Talwar GP, Dar SA, Rai MK: A novel polyherbal microbicide with inhibitory effect on bacterial, fungal and viral genital pathogens. Int J Antimicrob Agents 2008, 32:180-185.

27. Souad K, Ali S, Mounir A, Mounir TM: Spermicidal activity of extract from Cestrum parqui. Contraception 2007, 75:152-156.

28. Dubey R, Dubey K, Sridhar C, Jayaveera KN: Sperm immobilization activity of aqueous, methanolic and saponins extract of bark of Ziziphus Mauritiana. Pelagia Res Libr Der Pharmacia Sinica 2010, 1(3):151-156.

29. World Health Organization: Towards universal access, Progress Report. Geneva: WHO; 2010.

30. Treter J, Peixoto MPG, Giordani RB: Anti-Trichomonas vaginalis activity of saponins from Ilex paraguariensis ("Mate") fruits. Lat Am J Pharm 2010, 29(6):914-918.

31. Rocha TD, Vieira PB, Gnoatto SCB, Tasca T, Gosmann G: Anti-Trichomonas vaginalis activity of saponins from Quillaja, Passiflora, and Ilex species. Parasitol Res 2012, 110:2551-2556.

32. Richardson BA, Martin HL Jr, Stevens CE: Use of Nonoxynol-9 and Changes in Vaginal Lactobacilli. J Infect Dis 1998, 178:441-445.

33. Consolaro MEL, Siqueira VLD: Microbiologia Cérvico-Vaginal. In Citologia Clínica Cérvico-Vaginal: Texto e Atlas. Edited by Consolaro MEL, Maria-Engler SS. São Paulo: Roca; 2012:73-94.

34. Forbes A, Heise L: What's up with nonoxynol-9? Reprod Health Matters 2000, 8:156-159.

35. Richardson BA, Lavreys L, Martin HL, Stevens CE, Ngugi E, Mandaliya K, Bwayo J, Ndinya-Achola J, Kreiss JK: Evaluation of a low dose nonoxynol-9 gel for the prevention of sexually transmitted diseases: a randomized clinical trial. Sex Transm Dis 2001, 28:394-400.

36. Kirby J: Nonoxynol-9 may increase HIV transmission risk. Post Living 2001, 10:20 
37. Falagas ME, Betsi Gl, Athanasiou S: Probiotics for prevention of recurrent vulvovaginal candidiasis: a review. J Antimicrobial Chemotherapy 2006, 58:266-272.

38. Sweet SP, MacFarlane TW, Samaranayake LP: Determination of cell surface hydrophobicity of oral bacteria using a modified hydrocarbon adherence method. FEMS Microbiol Lett 1987, 48:159-168.

39. Sanders ME, Klaenhammer TR: Invited review: the scientific basis of Lactobacillus acidophilus NCFM functionality as a probiotic. J Dairy Sci 2001, 84:319-331.

doi:10.1186/1472-6882-13-196

Cite this article as: Damke et al: Spermicidal and anti-Trichomonas vaginalis activity of Brazilian Sapindus saponaria. BMC Complementary and Alternative Medicine 2013 13:196.

\section{Submit your next manuscript to BioMed Central and take full advantage of:}

- Convenient online submission

- Thorough peer review

- No space constraints or color figure charges

- Immediate publication on acceptance

- Inclusion in PubMed, CAS, Scopus and Google Scholar

- Research which is freely available for redistribution 